\title{
Factors Predicting outcome of patients with polytrauma in tertiary center of western Nepal.
}

\author{
Pradeep Ghimire ${ }^{1}$, Nikunja Yogi ${ }^{2}$, Balgopal Karmacharya ${ }^{2}$, Abhishek Poudel ${ }^{3}$, Sushil Mishra ${ }^{3}$ \\ ${ }^{1}$ Associate Professor (General Surgery), ${ }^{2}$ Associate Professor (Neurosurgery), ${ }^{3}$ Resident (General Surgery), Manipal College of \\ Medical Sciences, Pokhara, Nepal.
}

Received: January 27, 2021

Accepted: February 20, 2021

Published: March 30, 2021

Cite this paper:

Ghimire P, Yogi N, Karmacharya B, Poudel A, Mishra S. Factors Predicting outcome of patients with polytrauma in tertiary center of western Nepal. Journal of Brain and Spine Foundation Nepal. 2021:2(1):13-18.

Correspondence:

Pradeep Ghimire

Asoociate Professor and Head

Department of Surgery

Manipal, College of Medical Sciences, Pokhara, Nepal.

Email: pradeeppg757@ hotmail.com

ORCID: https://orcid.org/0000-0002-7104-8517

\begin{abstract}
:
Introduction: Trauma is a public health issue associated with substantial socioeconomic impacts and major adverse clinical outcomes. No single study has previously investigated the predictors of mortality in a general trauma population. In this study, we assessed different clinico-biochemical parameters to investigate the associations between those parameters and their effects in outcome of a polytrauma patient. Methods: An analytical study was done in between January 2020 to December 2020 in patients with polytrauma admitted to intensive care unit Department of Surgery in Manipal Teaching Hospital to assess the effect of various socio-demographic and clinic-radiologic variables in outcome (Glasgow outcome scale) of polytrauma patients. All the categorical data were tested using chi square test or Fischer Exact test and continuous variables were tested using student's " $t$ " test. P value $<0.05$ was determined significant. Those independent variables significant on univariate analysis were then subjected to binary logistic regression and the data was presented as level of significance, odds ratio and $95 \%$ confidence interval. Analysis was done using SPSS 23.0. Results: Out of 67 patients, 34 had favorable GOS and 33 had unfavorable GOS. Injury Severity Score (ISS) ( $\mathrm{P}<0.01)$, abnormal pupils ( $\mathrm{P}<0.01)$, RBS (0.04), low GCS during presentation $(<0.01)$, higher CT Marshal Grade (0.01) had strong associations with unfavorable outcome in polytraumatic patient. ISS was the only significant parameter when all the other significant variables were kept constant in binary logistic regression model $(\mathrm{OR}=1.18$, 95\% CI=1.08-1.28). Conclusion: Injury Severity Score, abnormal pupils during presentation, high level of blood sugar after polytrauma, low GCS during presentation, higher CT Marshal Grade are strong predictors in outcomes of polytraumatic patient.
\end{abstract}

Keywords: Glasgow coma scale, Polytrauma, Injury severity score, Glasgow outcome scale.

\section{Introduction:}

Trauma is a public health issue and associated with substantial socioeconomic impacts and major adverse clinical outcomes. No single study has previously investigated the predictors of mortality across all stages of care (pre-hospital, emergency room, surgical center and intensive care unit) in a general trauma population. The term "polytrauma" has been used interchangeably with multi trauma and has been frequently defined in terms of AIS and other clinic-biochemical parameters. 
According to new Berlin definition, Poly trauma includes cases with an Abbreviated Injury Scale (AIS) $\geq$ 3 for two or more different body regions with additional one or more variables from five physiologic parameters, including hypotension (systolic blood pressure $\leq 90$ $\mathrm{mmHg}$ ), unconsciousness (Glasgow Coma Scale score $\leq$ 8 ), acidosis (base excess $\leq-6.0$ ), coagulopathy (partial thromboplastin time $\geq 40 \mathrm{~s}$ or international normalized ratio $\geq 1.4)$, and age ( $\geq 70$ years $){ }^{1}$

Different Scoring systems have been developed in response to an increasing emphasis on the evaluation and monitoring traumatic patients, scoring system like Glasgow coma scale (GCS), Acute Physiology and Chronic Health Evaluation II (APACHE II), Revised Trauma Score (RTS), Injury Severity Score (ISS), Abbreviated injury score (AIS), Trauma Revised Injury Severity Score (TRISS) and Therapeutic Intervention Score (TISS)] in predicting the outcome in critically ill polytraumatized patients. Beside from different Scoring system, certain hematological and biochemical parameters have been used as predictors in assessing the outcomes in polytrauma in different literatures. ${ }^{2}$

In this study, we hypothesized that different clinicobiochemical parameters may predict the outcomes in polytraumatized patient. To pursue this question, we utilized retrospective data from our center to investigate the associations between those parameters and their effects in outcome of a polytrauma patient.

\section{Methods:}

An analytical study was done in between January 2020 to December 2020 in patients with polytrauma admitted to intensive care unit (General surgical and Neurosurgery) of Department of Surgery in Manipal Teaching Hospital, Pokhara, Nepal. Data were collected from the Medical Record Department of the hospital on various patients and injury characteristics. Poly trauma was defined as the New Berlins definition in our study. ${ }^{1}$
Patient of both gender and age above 18 years were included in the study. During data analysis, patients without polytrauma (AIS <3) were excluded. Data for gender, age, trauma mechanism and medical procedures performed during emergency, time to arrive at the hospital after trauma and associated comorbidities were recorded. Certain clinical parameters like systolic blood pressure (SBP), diastolic blood pressure (DBP), heart rate $(\mathrm{HR})$, respiratory rate $(\mathrm{RR})$, Glasgow coma score (GCS), and pupillary response were recorded. Injury severity score (ISS) and Marshalls CT classification ${ }^{3}$ and various laboratory investigations like sodium $(\mathrm{Na}+)$, potassium $(\mathrm{K}+)$, glucose, hemoglobin $(\mathrm{Hb})$, hematocrit (PCV), platelet counts, total leukocyte counts (TLC) and coagulation profile were recorded from the records. Outcome was assessed as Glasgow outcome scale (GOS) at discharge of the patients (Table 1). The total outcome score was noted from the chart of the patients and was dichotomized in to two groups; favorable GOS (GOS 4 and 5) and unfavorable GOS (GOS 1,2 and 3). Patients with incomplete data were also excluded from the study. Since the study was done in peak period of COVID, we find it important to mention that none of the COVID positive patients were included in this study as such positive patients were managed in separate ICU as per our hospital policy and thus the records did not contain any patients with COVID.

Various Clinic-demographic parameters were tested for association against outcome groups for association. All the categorical data were tested using chi square test or Fischer Exact test whenever chi-square was not feasible (any cells value less than 5) and continuous variables were tested using student's " $\mathrm{t}$ " test. $\mathrm{P}$ value $<0.05$ was determined significant. Those independent variables significant on univariate analysis were then subjected to binary logistic regression and the data was presented as 
level of significance, odds ratio and $95 \%$ confidence interval. Analysis was done using SPSS 23.0.

\section{Table 1. Glasgow Outcome Scale}

1 Death.

2 Neurovegetative state; patient unresponsive and speechless for weeks and month

3 Severe disability; patient's dependent in daily support.

4 Moderate disability; patient independent in daily life

5 Good recovery; resumption of normal life with minor neurological and psychological deficits

\section{Results:}

Out of 67 patients, 34 had favorable GOS and 33 had unfavorable GOS. Various clinic-demographic factors were tested for association with outcomes and the results are tabulated in Table 2. Abnormal Pupils, RBS, Glasgow coma scale, Injury Severity Score, Marshall CT Head Classification were the only variables showing statistically significant association with outcome. The independent variables found significant was further subjected to binary logistic regression which showed that Injury Severity Score (ISS) was the only variable significant with an odd of 1.18 while all the other independent variables were kept constant. Similarly, the odds ratio and 95\% confidence levels of other independent variables subjected to binary logistic regression has been tabulated in Table 3 .

\section{Discussion:}

In our context, hypotension and altered sensorium during presentation, multiple bodily injuries, failure to reach the trauma center by the golden time, trauma under the influences of drugs or alcohol are the main issues in emergency and trauma medicine. ${ }^{4}$ Although the transportation time may be short, polytrauma patients admitted to a trauma center usually already have a state of shock, hypoxia and coagulopathy. There is evidence that the disarrangement of the biochemical parameters occurs immediately after trauma and is directly proportional with each other. ${ }^{5-7}$ The main objective of this study was to assess those parameters and their role in predicting the outcomes in polytrauma patients.

In our study, $77.7 \%$ of the population has unfavorable outcomes as they were under the influence of alcohol as compare with favorable one (22.3\%). Consumption of the alcohol has a greater impact in patient health and consciousness level. The reason for unfavorable outcome in our study could be the high incident of fall, Road traffic accident and assault under the influence of alcohol in subconscious mind.

Mechanisms of injury have direct effects on outcome of polytraumatic patient; motor vehicle accident is the primary cause of polytrauma which can be evident in different studies followed by fall and assault. However, fall injury (49.3\%) was the most common cause of mechanism of injury after the road traffic accident $(41.8 \%)$ in our study.

ISS score characterize the severity of injury according to the anatomic region, and indirectly indicate the mass of destroyed tissue in the patient. ${ }^{8}$ Tissue destruction is associated with activation of the blood coagulation cascade leads to the consumption of blood clotting factors leading to activation of the vicious cycle which further cause bleeding and activation of 'triad of death' (coagulopathy, hypothermia, and acidosis), leading to the death of the patient. ${ }^{910}$ The data reported here indicates that the ISS is $20.53 \pm 9.87$ in favorable group and 36.24 \pm 9.92 in unfavorable group respectively with $\mathrm{p}$ value of $<0.01$ which is statistically significant. In multiple regression analysis it was also seen that ISS was the only significant predictor for outcome of polytrauma with an odds ratio of 1.18 (95\% CI,1.08-1.28). 


\begin{tabular}{|c|c|c|c|c|}
\hline S.N. & Parameters & Favorable GOS (34) & Unfavorable GOS (33) & $\mathrm{P}$ value \\
\hline \multirow[t]{3}{*}{1} & Gender & & & 0.59 \\
\hline & Male & $26(38.8 \%)$ & $27(40.3 \%)$ & \\
\hline & female & $8(11.9 \%)$ & $6(9.0 \%)$ & \\
\hline \multirow[t]{4}{*}{2} & Mechanism of Trauma & & & 1.00 \\
\hline & Assault & $3(4.5 \%)$ & $3(4.5 \%)$ & \\
\hline & Fall & $17(25.4 \%)$ & $16(23.9 \%)$ & \\
\hline & RTA & $14(20.9 \%)$ & $14(20.9 \%)$ & \\
\hline \multirow[t]{3}{*}{3} & Alcohol & & & 0.72 \\
\hline & Yes & $7(10.4 \%)$ & $8(11.9 \%)$ & \\
\hline & No & $27(40.3 \%)$ & $25(37.3 \%)$ & \\
\hline \multirow[t]{3}{*}{4} & Abnormal Pupils & & & $<0.01 *$ \\
\hline & Yes & $6(9.0 \%)$ & $18(26.9 \%)$ & \\
\hline & No & $28(41.8 \%)$ & $15(22.4 \%)$ & \\
\hline 5 & Age & $36.85 \pm 19.30$ & $43.58 \pm 21.41$ & 0.18 \\
\hline 6 & Time to present to the Hospital (hrs) & $4.65 \pm 5.28$ & $4.48 \pm 2.70$ & 0.88 \\
\hline 7 & SBP & $121.18 \pm 33.73$ & $123.64 \pm 28.04$ & 0.75 \\
\hline 8 & HR & $86.97 \pm 17.20$ & $90.79 \pm 20.25$ & 0.41 \\
\hline 9 & $\mathrm{SPO} 2$ & $91.32 \pm 6.66$ & $92.24 \pm 4.63$ & 0.52 \\
\hline 10 & $\mathrm{RR}$ & $21.18 \pm 3.20$ & $22.12 \pm 3.31$ & 0.23 \\
\hline 11 & $\mathrm{Hb}$ & $12.55 \pm 2.19$ & $12.21 \pm 1.97$ & 0.50 \\
\hline 12 & $\mathrm{PCV}$ & $34.27 \pm 9.01$ & $34.16 \pm 7.56$ & 0.96 \\
\hline 13 & PLT & $249.18 \pm 95.48$ & $230.18 \pm 92.01$ & 0.41 \\
\hline 14 & TLC & $14.43 \pm 5.56$ & $13.58 \pm 6.28$ & 0.56 \\
\hline 15 & INR & $1.38 \pm 0.26$ & $1.38 \pm 0.25$ & 0.96 \\
\hline 16 & RBS & $136.97 \pm 43.57$ & $164.21 \pm 60.23$ & $0.04 *$ \\
\hline 17 & GCS & $9.91 \pm 2.50$ & $7.45 \pm 3.75$ & $<0.01 *$ \\
\hline 18 & Marshal CT grade & $2.56 \pm 1.42$ & $3.52 \pm 1.50$ & $0.01 *$ \\
\hline 19 & ISS & $20.53 \pm 9.87$ & $36.24 \pm 9.92$ & $<0.01^{*}$ \\
\hline
\end{tabular}

\begin{tabular}{lllll}
\hline \multicolumn{5}{l}{ Table 3. Binary Logistic Regression analysis of significant predictors of outcome } \\
\hline S.N & Independent Variables & P value & Odds Ratio & $95 \%$ CI \\
1 & RBS & 0.28 & 1.01 & $0.99-1.03$ \\
2 & Abnormal Pupils & 0.06 & 5.38 & $0.97-29.95$ \\
3 & ISS & $<0.01^{*}$ & 1.18 & $1.08-1.28$ \\
4 & Marshall CT classification & 0.55 & 1.17 & $0.69-1.99$ \\
\hline
\end{tabular}


In our study it is seen that unfavorable group have high RBS than the favorable group i.e., $164.21 \pm 60.23$ and $136.97 \pm 43.57$ respectively with statistically significant $p$ value. Blood glucose level increase in acute polytrauma occurs as a response to stress and injury severity, even this increase can remain 72 hours after the event. ${ }^{8}$ Hyperglycemia during the acute injuries is induced by both increased glucose production and decreased glucose cellular uptake. High levels of glucose are produced through up-regulation of both gluconeogenesis and glycogenolysis. In addition, in polytrauma increase in cortisol, catecholamine, and cytokine levels also induces hyperglycemia. ${ }^{11}$

GCS is an important prognostic factor of outcome in polytrauma as it reflects the severity of TBI, a most important part of polytrauma. ${ }^{12-14}$ In our Glasgow Coma Score were relatively low in unfavorable $(7.45 \pm 3.75)$ group as compared with favorable one $(9.91 \pm 2.50)$ with significant $p$ value $(<0.01)$. The cause for low level of GCS could be concomitant cranial injury of various severities or patient might be in a state of shock. GCS have an important impact on mortality and morbidity in polytrauma patients, patient with low GCS have high severity of traumatic brain injury. This can be evident by a study done by Steyerberg ew et al. showed that there is association between mortality and GCS score is for each increased GCS point corresponded to a $2 \%$ decrease in mortality. ${ }^{15}$ Likewise, a study done by Kuhls et al. showed age and GCS yields higher discriminatory power in mortality prediction in trauma. ${ }^{16}$ Similarly, abnormal pupillary response and higher Marshall CT grades were also found to have association with unfavorable outcomes in our study implication higher the degree of TBI, poorer the outcome in polytrauma.

Conclusions: Injury Severity Score, abnormal pupils during presentation, high level of blood sugar after polytrauma, low GCS during presentation, higher CT
Marshal Grade are strong predictors in outcomes of polytraumatic patient.

\section{Reference:}

1. Rau CS, Wu SC, Kuo PJ, Chen YC, Chien PC, Hsieh HY, Hsieh CH. Polytrauma Defined by the New Berlin Definition: A Validation Test Based on PropensityScore Matching Approach. Int J Environ Res Public Health. 2017;14(9):1045. https://doi.org/10.3390/ijerph14091045

2. Okasha SA, Abouelela A, Hashish W. Prediction of outcome of poly traumatized patients using different trauma scoring systems. J Amer Sci. 2011;7(12):281-91.

3. Marshall LF, Marshall SB, Klauber MR, Van Berkum Clark M, Eisenberg H, Jane JA et al. The diagnosis of head injury requires a classification based on computed axial tomography. J Neurotrauma. 1992;9 Suppl 1:S28792. PMID: 1588618.

4. Yogi N, Karmacharya BG, Gurung A. Clinical predictors of abnormal Computed Tomography findings in mild head injury. Nepalese Journal of Radiology 2018;8(12):20-25. https://doi.org/10.3126/njr.v8i2.22978.

5. Spahn DR, Bouillon B, Cerny V, Coats TJ, Duranteau J, Fernández-Mondéjar E et al. Management of bleeding and coagulopathy following major trauma: an updated European guideline. Crit Care. 2013;17(2):R76. https://doi.org/10.1186/cc12685.

6. Mica L, Rufibach K, Keel M, Trentz O. The risk of early mortality of polytrauma patients associated to ISS, NISS, APACHE II values and prothrombin time. J Trauma Manag Outcomes. 2013;24;7:6. https://doi.org/10.1186/1752-2897-7-6.

7. Berkeveld E. Popal Z, Schober, Zuidema WP, Bloemers FW, Giannakopoulos GF. Prehospital time and mortality in polytrauma patients: a retrospective analysis. BMC Emerg Med. 2021;21:78. https://doi.org/10.1186/s12873-021-00476-6.

8. Baker SP, o'Neill B, Haddon Jr W, Long WB. The injury severity score: a method for describing patients with multiple injuries and evaluating emergency care. J 
Trauma.

1974;14(3):187-96.

https://doi.org/10.1097/00005373-197403000-00001.

9. Peng $\mathrm{N}, \mathrm{Su}$ L. Progresses in understanding traumainduced coagulopathy and the underlying mechanism.

Chin J Traumatol. 2017;20(3):133-136.

https://doi.org/10.1016/j.cjtee.2017.03.002.

10. Martini WZ. Coagulation complications following trauma. Mil Med Res. 2016;3:35. https://doi.org/10.1186/s40779-016-0105-2.

11. Alvis-Miranda HR, Navas-Marrugo SZ, VelasquezLoperena RA, Adie-Villafañe RJ, Velasquez-Loperena D, Castellar-Leones SM, et al. Effects of Glycemic Level on Outcome of Patients with Traumatic Brain Injury: A Retrospective Cohort Study. Bull Emerg Trauma. 2014;2(2):65-71. https://doi.org/10.5005/jp-journals10030-1066.

12. Boyd CR, Tolson MA, Copes WS. Evaluating trauma care: the TRISS method. Trauma Score and the Injury Severity Score. J Trauma. 1987;27(4):370-8. https://doi.org/10.1097/00005373-198704000-00005.

13. Hampton DA, Lee TH, Diggs BS, McCully SP, Schreiber MA. A predictive model of early mortality in trauma patients. Am J Surg. 2014;207(5):642-7. https://doi.org/10.1016/j.amjsurg.2013.12.009.

14. Cudworth M, Fulle A, Ramos JP, Arriagada I. GCS as a predictor of mortality in patients with traumatic inferior vena cava injuries: a retrospective review of 16 cases. World J Emerg Surg. 2013;8(1):59. https://doi.org/10.1186/1749-7922-8-59.

15. Majdan M, Lingsma HF, Nieboer D, Mauritz W, Rusnak M, Steyerberg EW. Performance of IMPACT, CRASH and Nijmegen models in predicting six-month outcome of patients with severe or moderate TBI: an external validation study. Scandinavian journal of trauma, resuscitation and emergency medicine. 2014;22(1):1-0. https://doi.org/10.1186/s13049-014-0068-9.

16. Kuhls DA, Malone DL, McCarter RJ, Napolitano LM. Predictors of mortality in adult trauma patients: the physiologic trauma score is equivalent to the Trauma and Injury Severity Score. J Am Coll Surg. 2002;194(6):695-

704. https://doi.org/10.1016/S1072-7515(02)01211-5. 